\title{
Effects of Zn-Based Alloys Coating on Mechanical Properties and Interfacial Microstructures of Steel/Aluminum Alloy Dissimilar Metals Joints Using Resistance Spot Welding*1
}

\author{
Keisuke Ueda ${ }^{1, * 2}$, Tomo Ogura ${ }^{1}$, Shumpei Nishiuchi ${ }^{1, * 3}$, Kenji Miyamoto ${ }^{2}$, \\ Toshikazu Nanbu ${ }^{2}$ and Akio Hirose ${ }^{1}$ \\ ${ }^{1}$ Division of Materials and Manufacturing Science, Osaka University, Suita 565-0871, Japan \\ ${ }^{2}$ Nissan Motor Co. Ltd., Yokosuka 237-8523, Japan
}

The effects of Zn-based alloys coating ( $\mathrm{Zn}, \mathrm{Al}-\mathrm{Zn}$ and Al-Mg-Zn) on the bondability of steel/aluminum alloy dissimilar metals joints were evaluated, in order to achieve strength in lower welding current. In the joint with Zn-based alloys insert, the oxide film on the aluminum alloy was sufficiently removed through eutectic reaction of Zn-based alloys and aluminum. In the joint with Zn-coated steel (GI), higher welding current is necessary to discharge the zinc coating and the oxide film from the bonding interface sufficiently. The thinner aluminum plate after welding and the thick reaction layer cause the decrease of cross tensile strength in the joints with no coating steel (SPCC) and Al-Zn-coated steel. Using Al-Mg-Zn-coated steel, higher strength was achieved in a lower welding current. This is because Al-Mg-Zn-coating melted at lower temperature than $\mathrm{Zn}$ and Al-Zn-coating, and the removal of the coating material and the oxide film on the aluminum alloy were sufficiently performed in the lower welding current. [doi:10.2320/matertrans.L-MZ201108]

(Received October 1, 2010; Accepted November 29, 2010; Published April 20, 2011)

Keywords: dissimilar metals joining, aluminum alloy, zinc-coated steel, resistance spot welding, eutectic reaction

\section{Introduction}

The issues of warming and energy consumption have been global social problems. In automobile industries, many companies have taken various provision, the most important one is the improvement of fuel consumption by reducing car weight, ${ }^{1,2)}$ for which usage of lighter materials than steel such as aluminum alloys is effective. However, it is difficult to apply these materials for the whole car body from the view point of productivity and cost. Therefore, multi-materials structures using steels and aluminum alloys are considered to be efficient.

For the application of steel/aluminum alloy dissimilar metals joints, one of the most important issue is to remove the oxide film formed on the surface of steel and aluminum alloy. ${ }^{1,3,4)}$ The effective removal of the oxide film is the application of zinc coating between steel and aluminum alloy through the melt of zinc. ${ }^{4)}$ As for the melt of $\mathrm{Zn}$-based alloys, it is well known that the eutectic point of Al-Zn binary alloy and $\mathrm{Al}-\mathrm{Mg}-\mathrm{Zn}$ ternary alloy is lower than the melting point of zinc. ${ }^{5)}$ Therefore, it is expected that the lower temperature bonding is achieved using Al-Zn binary and Al-Mg-Zn ternary coatings through eutectic reaction at lower temperature.

In this study, Zn-based alloys coated steels have been welded to 6000 series aluminum alloy using resistance spot welding with the objective of identifying the effects of the coatings on mechanical properties and interfacial microstructures of the joints.

\footnotetext{
${ }^{* 1}$ The Paper Contains Partial Overlap with the ICAA12 Proceedings by USB under the Permission of the Editorial Committee.

${ }^{*}$ Graduate Student, Osaka University

${ }^{* 3}$ Graduate Student, Osaka University. Present address: Toyo Engineering Corporation, Chiba 275-0024, Japan
}

Table 1 Chemical composition of cold rolled steel plate (mass\%).

\begin{tabular}{cccccc}
\hline & $\mathrm{C}$ & $\mathrm{Mn}$ & $\mathrm{P}$ & $\mathrm{S}$ & $\mathrm{Fe}$ \\
\hline SPCC & 0.15 & 0.60 & 0.05 & 0.05 & Bal. \\
\hline
\end{tabular}

Table 2 Chemical composition of aluminum alloy (mass\%)

\begin{tabular}{cccccccccc}
\hline Material & $\mathrm{Si}$ & $\mathrm{Fe}$ & $\mathrm{Cu}$ & $\mathrm{Mn}$ & $\mathrm{Mg}$ & $\mathrm{Cr}$ & $\mathrm{Zn}$ & $\mathrm{Ti}$ & $\mathrm{Al}$ \\
\hline Al alloy & 1.00 & 0.13 & 0.02 & 0.07 & 0.60 & 0.01 & 0.01 & 0.02 & $\mathrm{Bal}$.
\end{tabular}

Table 3 Chemical compositions (at $\%$ ) and melting point (K) of coating materials and the thickness of coating steels.

\begin{tabular}{cccccc}
\hline & Mg & Al & Zn & $\begin{array}{c}\text { Melting } \\
\text { point }(\mathrm{K})\end{array}$ & $\begin{array}{c}\text { Thickness of } \\
\text { coating steel }(\mathrm{mm})\end{array}$ \\
\hline GI & & - & 100 & 693 & 0.6 \\
\hline Al-Zn coating & - & 55.0 & 45.0 & 823 & 1.2 \\
\hline Al-Mg-Zn coating & 2.0 & 5.0 & Bal. & 623 & 1.2 \\
\hline
\end{tabular}

\section{Experimental Procedure}

Four kinds of commercial steel, cold-rolled steel plate (SPCC), Zn-coated (GI), Al-Zn-coated and Al-Mg-Zn-coated steels were used in this study. Table 1 and Table 2 show the chemical compositions of SPCC and 6000 series aluminum alloy. The thickness of SPCC and aluminum alloy is 1.2 and $1.0 \mathrm{~mm}$, respectively. The chemical compositions and melting point of the coating materials of GI, Al- $\mathrm{Zn}$ and $\mathrm{Al}-\mathrm{Mg}-\mathrm{Zn}$ are shown in Table 3. SEM images of coating materials before bonding are shown in Fig. 1. The thickness of the coating in GI, Al-Zn and Al-Mg-Zn is 10,25 and $12 \mu \mathrm{m}$, respectively. In Al-Zn-coated steel, the reaction layer con- 

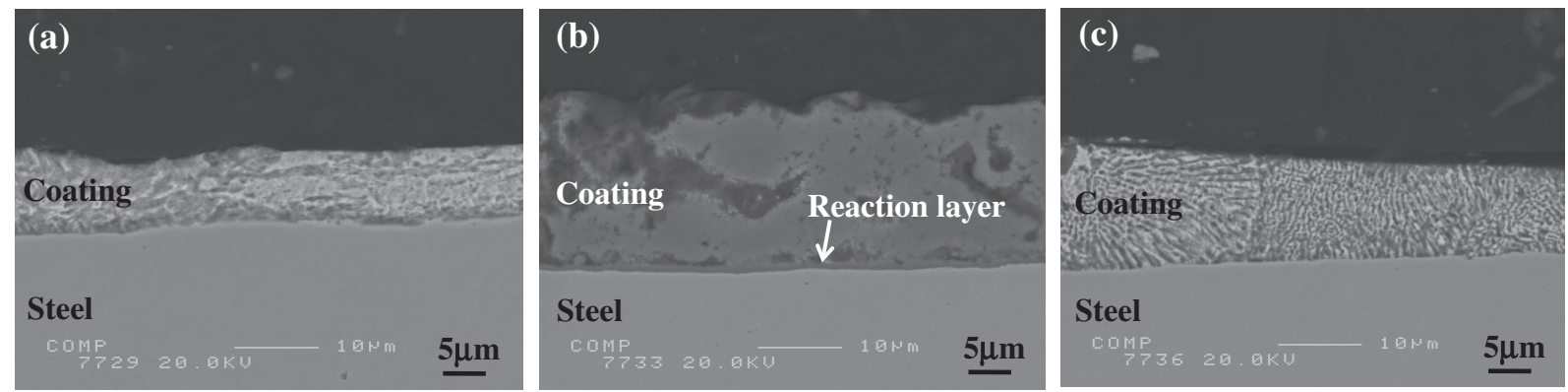

Fig. 1 SEM images of (a) GI, (b) Al-Zn-coated steel, and (c) Al-Mg-Zn-coated steel.

(a)

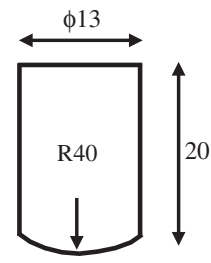

Radius type

(b)

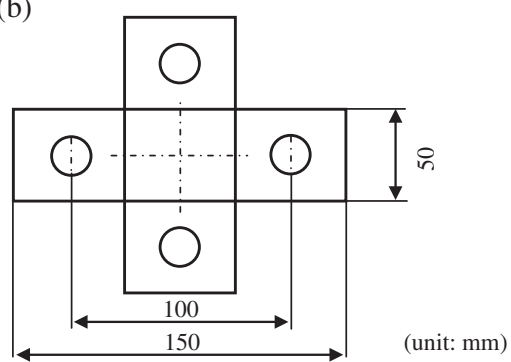

Fig. 2 Dimension of (a) the electrode shape and (b) the specimen for cross tensile test.

sidering aluminum-rich intermetalic compound (IMC) is also recognized between Al-Zn-coating and steel. The steel plates and aluminum alloy plates were welded by resistance spot welding after cleaning the surface by acetone. Welding current, time and electrode force are 10-30 kA, $0.24 \mathrm{~s}$ and $1176 \mathrm{~N}$, respectively. The shape of electrode is shown in Fig. 2(a). The interface of joints was analyzed by using stereomicroscope and scanning electron microscope (SEM) with an electron probe microanalysis (EPMA). The thickness of the reaction layer at the welding interface was measured using image analysis. The nugget diameter was also measured from stereomicroscope images after etching the surface of the joints. Cross tensile test was carried out with a cross-head speed of $5 \mathrm{~mm} / \mathrm{min}$ with the dimension as shown in Fig. 2(b).

\section{Results and Discussion}

\subsection{Effects of $\mathrm{Zn}$-based alloys coating on cross tensile strength of the joints}

A typical macrostructure of the joint after the resistance spot welding is shown in Fig. 3. The aluminum alloy plate was deformed thinner at the nugget by a welding current, because aluminum alloy melts and squeezed by electrode

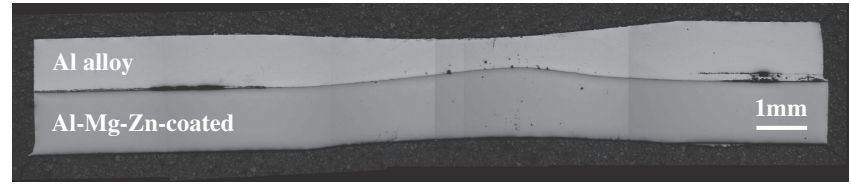

Fig. 3 Macrostructures of $\mathrm{Al}$ alloy/Al-Mg-Zn-coated steel in $15 \mathrm{kA}$.

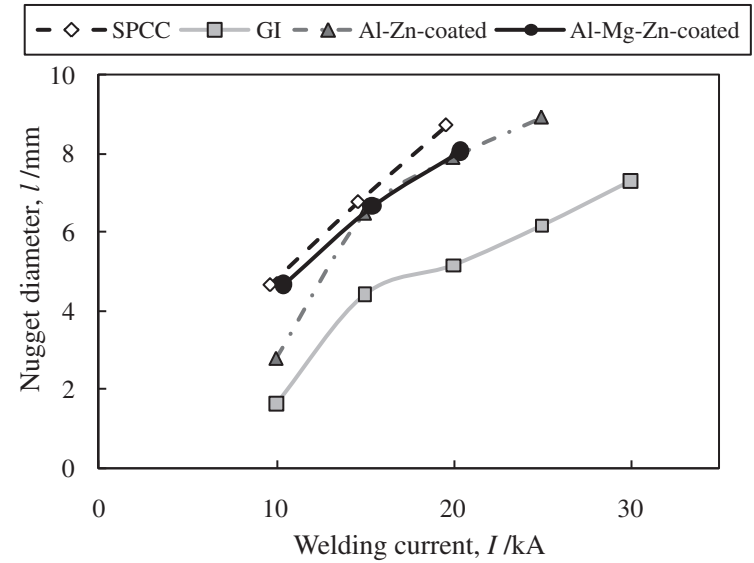

Fig. 4 Relationship between nugget diameter and welding current in $\mathrm{Zn}$ based alloy coated steel/aluminum alloy joints.

force. The thickness of the aluminum plate became thinner with increasing welding currents. The relationship between a nugget diameter and a welding current is shown in Fig. 4. With increasing a welding current, a nugget diameter was monotonously increased regardless of the coating materials in this welding current. The joints with GI have a small nugget diameter in comparison with other joints in all welding current. In the welding current more than $15 \mathrm{kA}$, three kinds of joints except GI showed almost the same nugget diameter.

Cross tensile test of the joints was performed in order to evaluate the mechanical properties of the joints. The obtained cross tensile strength is shown in Fig. 5. It was found that the joint strength with Al-Mg-Zn-coated steel shows the highest of four kinds of joints. Moreover, it should be noted that the higher strength with Al-Mg-Zn-coated steel was obtained at the lower welding current. From the fracture surface observation of the joints, it was recognized that interfacial fracture mainly occurred in the joints with lower tensile strength, whereas plug type fracture occurred in the joints 


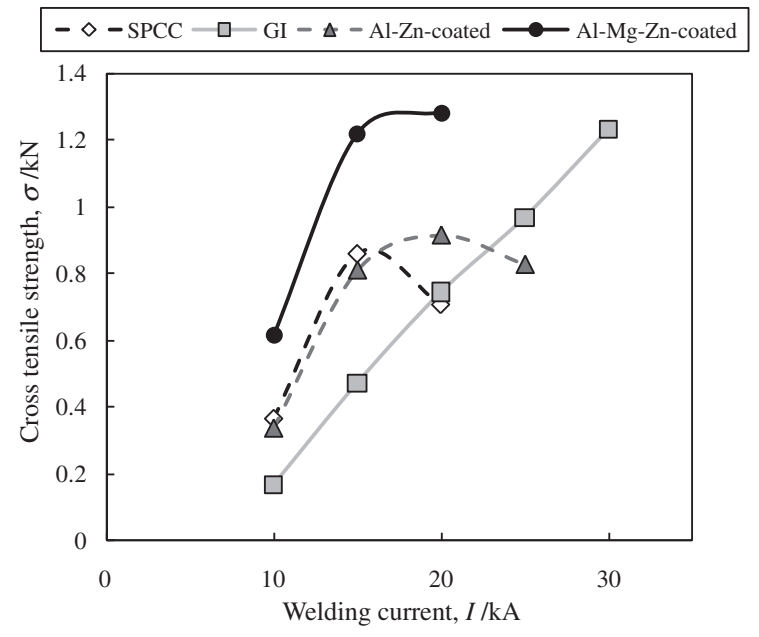

Fig. 5 Relationship between cross tensile strength and welding current in Zn-based alloy coated steel/aluminum alloy joints.

with higher tensile strength regardless of the coating materials. In the joints with SPCC and Al-Zn-coated steel, tensile strength decreased in higher welding currents. This is because the decrease in the thickness of aluminum alloy plate caused the fracture easily in higher welding currents. This fracture occurs in the case when the thickness was less than $0.3 \mathrm{~mm}$. Therefore, it is suggested that tensile strength of the joints is converged to a certain value.

\subsection{Effects of $\mathrm{Zn}$-based alloys coating on interfacial microstructures of the joints}

From the section 3.1, it was found that the strength with $\mathrm{Al}-\mathrm{Mg}-\mathrm{Zn}$-coated steel is higher than that with other coated steels, especially in the lower welding current. To understand these tensile properties in detail, we observed the interfacial microstructure at the center of the nugget of the joints in $20 \mathrm{kA}$ welding current using SEM. The results are shown in Fig. 6. In all joints, it was clearly seen that the reaction layer formed at the interface of the joint. The corresponding EPMA mappings of the interface are shown in Fig. 7. It was found that the reaction layers forming at the interface were composed of aluminum and iron in all joints. Although the quantitative analyses of the composition in these reaction layers are difficult because of the reaction layers are too thin to analyze chemical composition by EDX analysis. However, the reaction layers are considered to be aluminum-rich Al-Fe IMC, as normally observed in aluminum steel dissimilar joints in the precious works. ${ }^{6-8)}$ In the joint with SPCC, oxygen was not detected at the interface, showing that the oxide film on the surface of aluminum alloy is electrically and mechanically destroyed. In this time, however, the destruction of the oxide film and heating occur locally, resulting the ununiformity of the reaction layer formed as shown in Fig. 8. In the joint with GI, on the other hand, zinc and oxygen were detected at the interface, showing that the coating material and the oxide film on the aluminum alloy were not sufficiently discharged. In the joints with Al-Zncoated steel and Al-Mg-Zn-coated steel, zinc, magnesium, and oxygen were not detected in the interfacial region, indicating that coating materials were successfully pushed out from the bonding interface together with the oxide film.

To evaluate the charge of zinc and oxygen distributions with a welding current, EPMA mapping analysis was performed to the joints with GI in all welding currents in this work. The result is shown in Fig. 9. Zinc and oxygen were detected in the welding current of 10 to $20 \mathrm{kA}$, and they
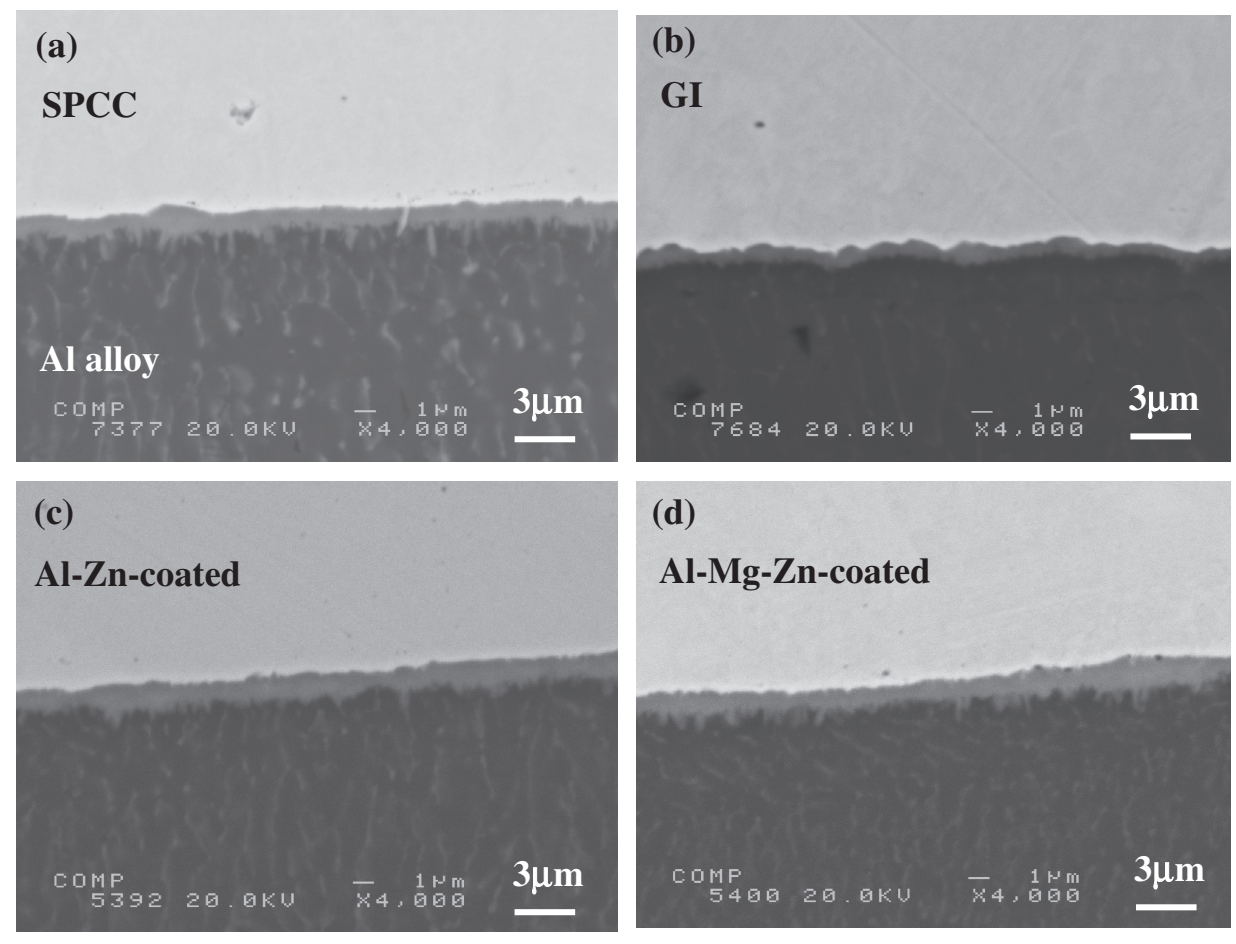

(d)

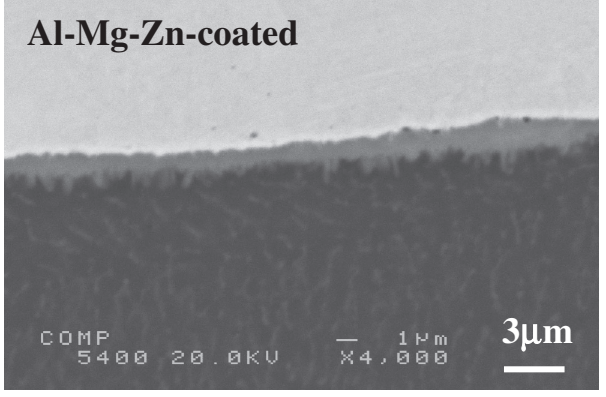

Fig. 6 SEM images of the interface in (a) SPCC, (b) GI, (c) Al-Zn-coated and (d) Al-Mg-Zn-coated steel/aluminum alloy joints. The welding current is $20 \mathrm{kA}$. 
(a)

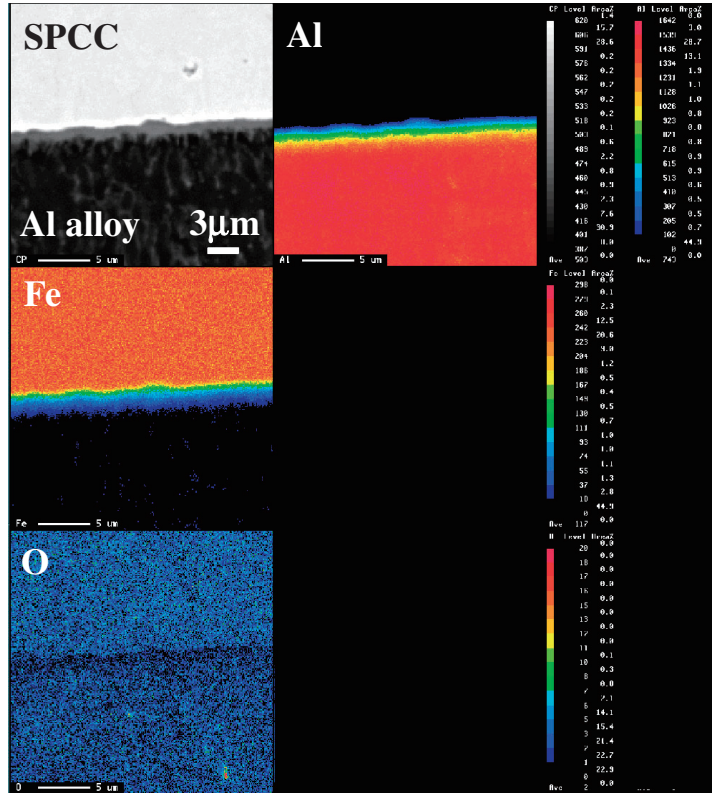

(c)

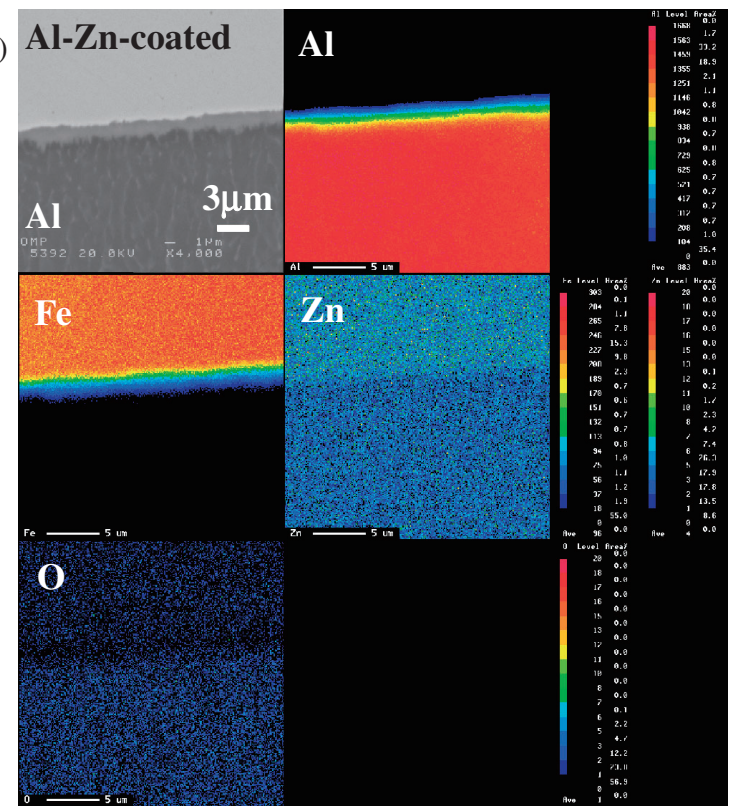

(b)

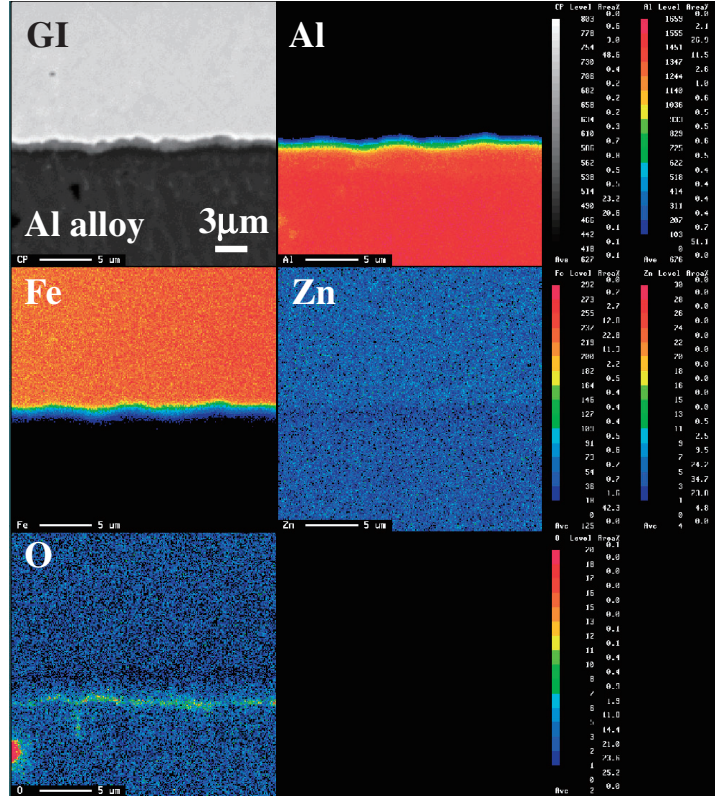

(d)

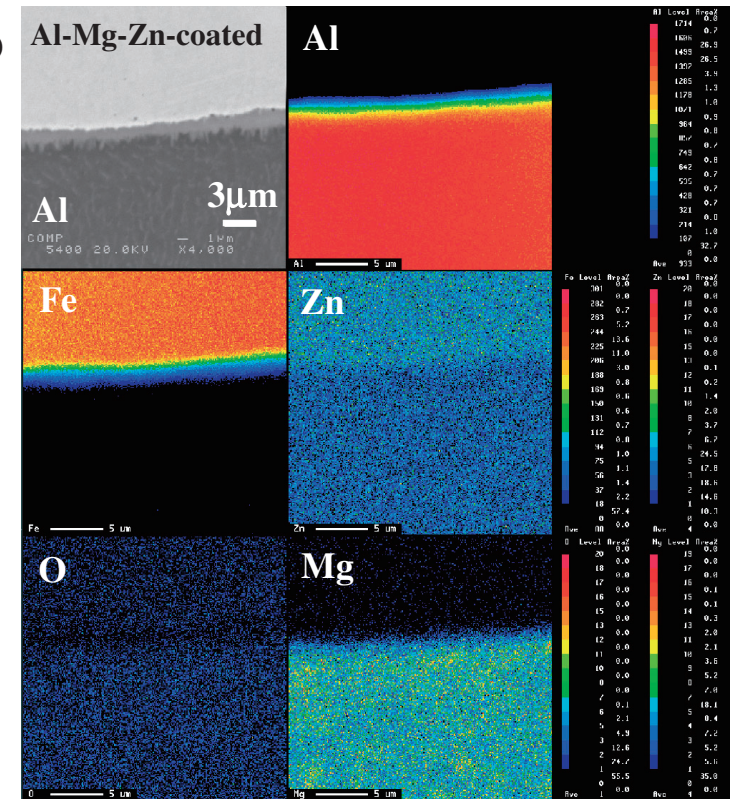

Fig. 7 EPMA mappings of the interface in (a) SPCC, (b) GI, (c) Al-Zn-coated steel and (d) Al-Mg-Zn-coated steel/aluminum alloy joints. The welding current is $20 \mathrm{kA}$.

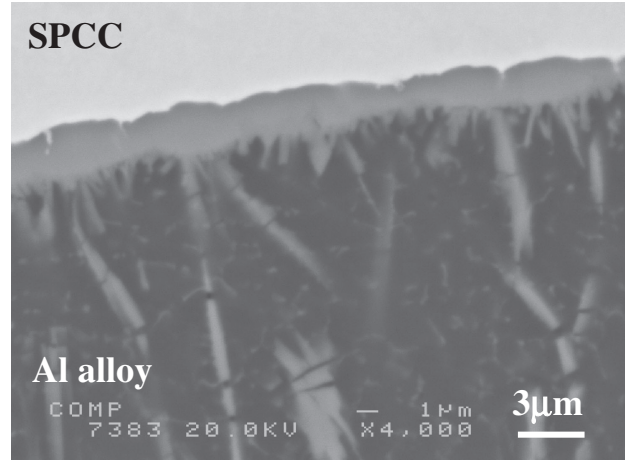

Fig. 8 SEM image of the interface in SPCC/aluminum alloy joint in $20 \mathrm{kA}$. were completely discharged in 25 and $30 \mathrm{kA}$. This result shows that zinc coating and oxide film are not completely discharged in the lower welding current. This residual zinc coating and oxide film in the lower welding current are considered to cause the lower tensile strength of GI/ aluminum joints (Fig. 5).

It is well known that the reaction layer at the interface significantly affects the strength of the joint. ${ }^{1,2,6-9)}$ Therefore, the joint strength is also discussed base on the thickness of the reaction layer. The average thickness of the reaction layer of the joints is shown in Fig. 10. In the welding current more than $15 \mathrm{kA}$, the joints with SPCC and Al-Zn-coated steel have the thicker reaction layer $(>1 \mu \mathrm{m})$ than the joints with GI and Al-Mg-Zn-coated steel. The reaction layer thickness of the joint with GI was the lowest of the four joints. The reaction layer of the joint with $\mathrm{Al}-\mathrm{Mg}-\mathrm{Zn}$-coated was almost 


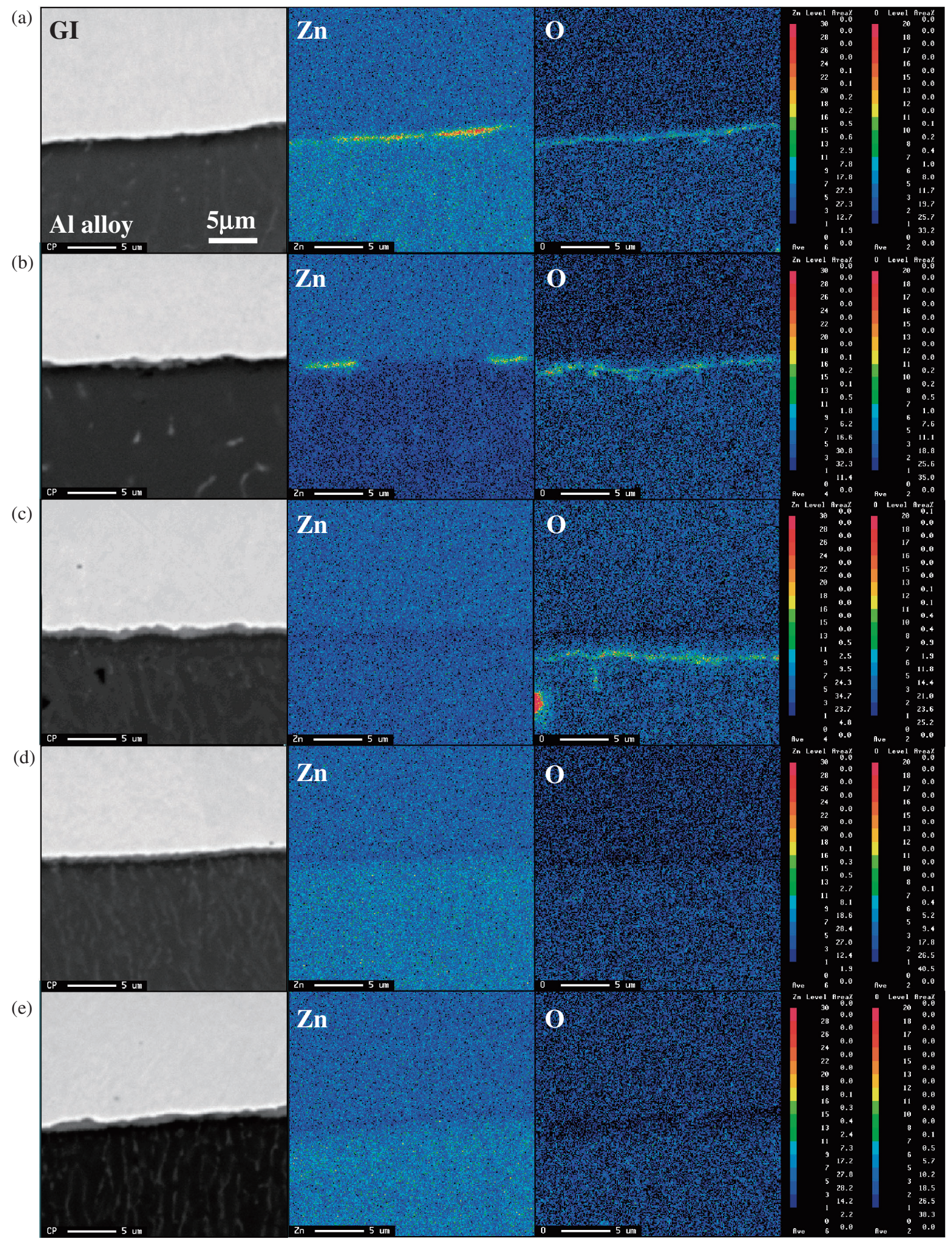

Fig. 9 EPMA mappings of GI/aluminum alloy joints. The welding current is (a) 10, (b) 15, (c) 20 , (d) 25 and (e) $30 \mathrm{kA}$.

unity. In the joint with SPCC, the temperature at the interface become higher than the other joints because no coating material causes limited current-carrying paths. Then local heating also occurs, resulting in the ununiform reaction layer as shown in Fig. 8. In the joint with Al-Zn-coated steel, the reaction layer are already formed between the coating and steel before welding as shown in Fig. 1(b). Therefore, it is thought that this reaction layer prevents the contact between fresh surface of steel and the aluminum alloy, and causes the remanent of thick reaction layer. In the diffusion bonding of steel and an aluminum alloy, our previous work have reported that joint strength decreases when the reaction layer thickness is above $1 \mu \mathrm{m} .{ }^{8,9)}$ Therefore, it is thought that the thicker reaction layer of the joints with SPCC and Al-Zn- 


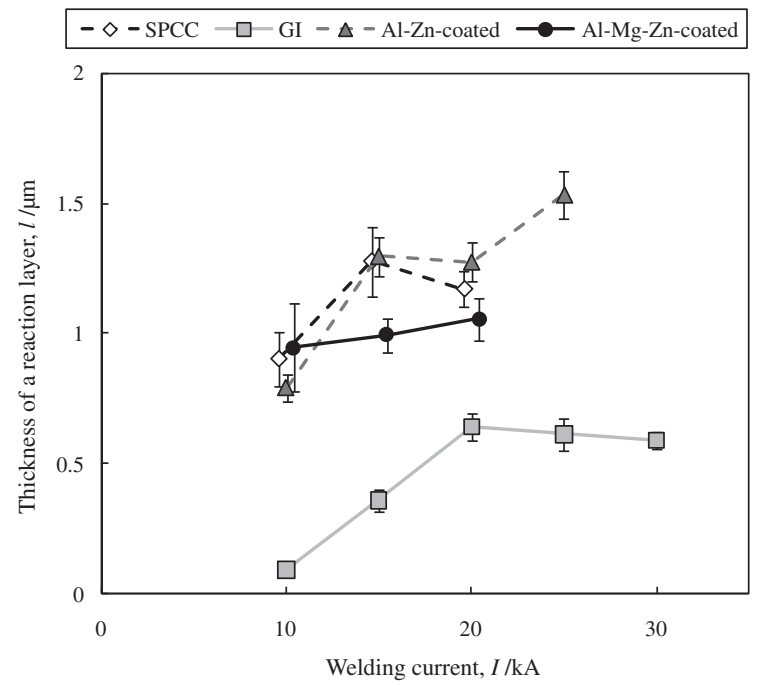

Fig. 10 Relationship between thickness of a reaction layer and welding current.

coated steel caused the lower tensile strength of these joints in more than $15 \mathrm{kA}$ in spite of increasing nugget diameter.

In the joint with GI, the thiner and uniform reaction layer formed due to the efficient eutectic reaction using zinc coating. In the joint with Al-Mg-Zn-coated steel, by the effect of the Al-Mg-Zn coating material, the uniform reaction layer formed like a joint with GI. Moreover the joining through the eutectic reaction is achieved by the lower welding current because of the lower melting point than zinc coating as shown in Table 3.

From the experimental results, it can be concluded that Al$\mathrm{Mg}-\mathrm{Zn}$ coating sufficiently removes the oxide film and forms the thiner reaction layer through $\mathrm{Al}-\mathrm{Mg}-\mathrm{Zn}$ eutectic reaction, which leads the higher strength of the steel/aluminum dissimilar joints.

\subsection{Bonding mechanism of $\mathrm{Zn}$-based alloy coating steel/ aluminum joints}

From the experimental results, the bonding mechanism of the four kinds of steel/aluminum alloy joints was discussed as follows. The schematic illustrations of the bonding process of $\mathrm{Zn}$-based alloy coating steel/aluminum alloy joints are shown in Fig. 11. Before resistance spot welding, the oxide film exists on the aluminum alloy regardless of steel with/ without the coating. In the joint with SPCC (Fig. 11(a)), the oxide film on the surface of aluminum alloy was destroyed due to electrode force and heat by the resistance. However, at this time, the destruction of the oxide film occurred partially, and heating which leads the diffusion of aluminum and iron at the interface also occurs locally, resulting in the ununiformity of the reaction layer through diffusion reaction.

In the joint with GI (Fig. 11(b)), the deformation of the oxide film occurs due to electrode force and heat by the resistance, same as the joint with SPCC. Aluminum and zinc begin to react, and Al-Zn eutectic liquid is formed at the interface, efficiently removing the oxide film. The eutectic liquid is discharged outside by the electrode force, and the

\section{(a)}

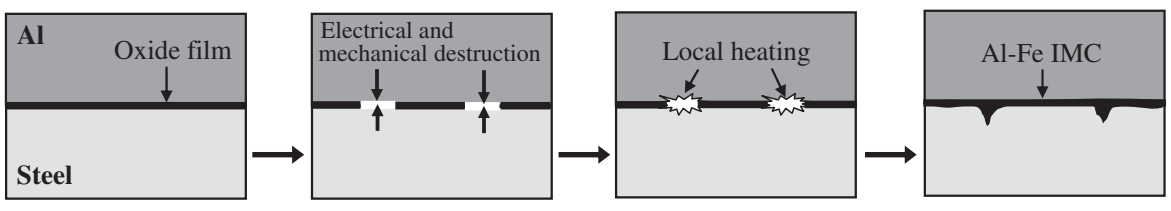

(b)

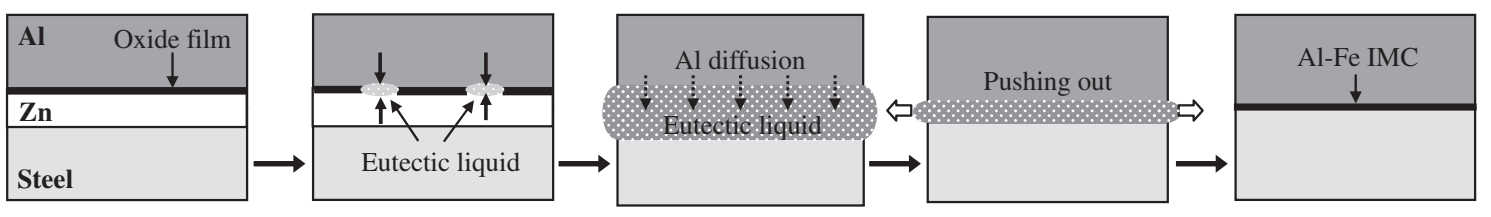

(c)

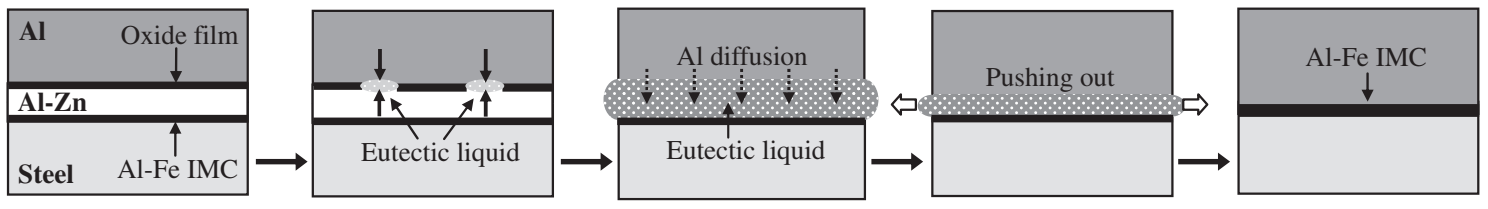

(d)

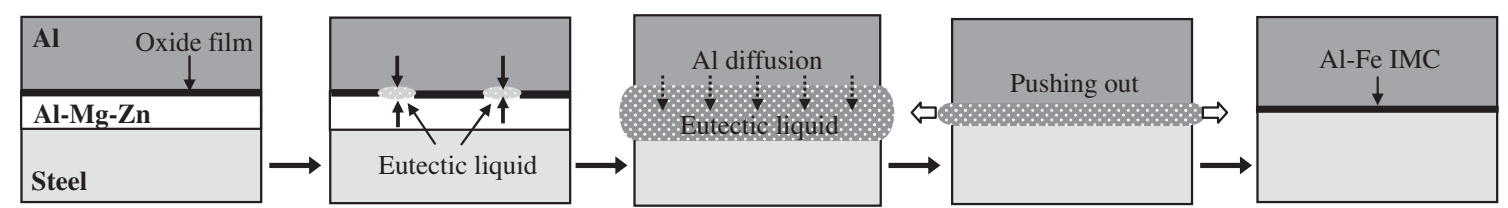

Fig. 11 Schematic illustrations of the bonding process of (a) SPCC, (b) GI, (c) Al-Zn-coated steel and (d) Al-Mg-Zn-coated steel/ aluminum alloy joints. 
newly-formed surface of the aluminum alloy attaches the surface of steel. Finally, aluminum-rich Al-Fe IMC reaction layer forms through the diffusion of aluminum and iron, and the metallurgical bonding is achieved.

In the joint with Al-Zn-coated steel (Fig. 11(c)), in addition to the oxide film on the surface of aluminum alloy, the reaction layer composed of aluminum and iron initially exists at the interface between steel and the coating material. Because a melting point of the reaction layer is higher than that of the coating material, it may remains at the interface even if the coating material begins to melt. The reaction layer prevents the contact between the newly-formed surface of steel and aluminum alloy, as a result, the thicker reaction layer forms at the interface.

Finally, the joint with Al-Mg-Zn-coated steel (Fig. 11(d)) follows the process like the joint with GI. Moreover, the joining is achieved by the lower electric current because a melting point of the Al-Mg-Zn coating is lower than GI, clearly showing that coating material and the oxide film on the aluminum alloy sufficiently removed in the low welding current. In this process, lower temperature bonding is achieved through the lower eutectic reaction.

\section{Conclusions}

In this study, in order to achieve higher strength at the lower welding current through eutectic reaction, the aluminum alloy and $\mathrm{Zn}$-based coated steel are welded by resistance spot welding. The obtained results were as follows:

(1) In the joint with SPCC, cross tensile strength decreases because of the thinner aluminum plate after welding and thicker reaction layer at the interface of joints.

(2) In the joints with Al-Zn-coated steel, cross tensile strength decreases as shown in the joints with SPCC. In addition, the reaction layer formed between the coating and steel before welding causes the thicker reaction layer.

(3) The joints with GI and Al-Mg-Zn-coated steel can be sufficiently welded removing an oxide film through eutectic reaction. Moreover, highest strength was achieved in the joint with $\mathrm{Al}-\mathrm{Mg}-\mathrm{Zn}$-coated steel by a lower welding current due to the lower melting point of the Al-Mg-Zn coating.

\section{Acknowledgement}

The authors would like to thank Mr. K. Ohmitsu for operating EPMA. A part of this work was supported by Priority Assistance for the Formation of Worldwide Renowned Centers of Research-The Global COE Program (Project: Center of Excellence for Advanced Structural Materials Design) from the Ministry of Education, Culture, Sports, Science and technology (MEXT) and Grant-in-Aid for Young Scientists (B) No. 21760585, Japan.

\section{REFERENCES}

1) A. Hirose: J. JSAE 61 (2007) 18-23.

2) S. Sasabe: J. JSAE 61 (2007) 24-29.

3) A. Manabe: Zairyo-to-Kankyo 48 (1999) 463-468.

4) K. Miyamoto, S. Nakagawa, C. Sugi, H. Sakurai and A. Hirose: SAE Int. J. Mater. Manuf. 2 (2009) 58-67.

5) P. Villars, A. Prince and H. Okamoto: Handbook of Ternary Alloys Phase diagrams Vol. 4, (ASM International, 1995) 3938-3985.

6) H. Oikawa, T. Saito, T. Nagase and T. Kiriyama: Tetsu to Hagane 83 (1997) 37-42.

7) A. Hirose, F. Matsui, H. Imaeda and K. F. Kobayashi: Mater. Sci. Forum 475-479 (2005) 349-352.

8) Y. Saito, H. Umeshita, T. Ogura and A. Hirose: Q. J. Jpn. Weld. Soc. 27 (2009) 187-191.

9) T. Ogura, H. Umeshita, Y. Saito and A. Hirose: Q. J. Jpn. Weld. Soc. 27 (2009) 174-178. 